\title{
Cyclic AMP Regulates Somatostatin mRNA Accumulation in Primary Diencephalic Cultures and in Transfected Fibroblast Cells
}

\author{
Marc R. Montminy, Malcolm J. Low, Lucia Tapia-Arancibia, Seymour Reichlin, \\ Gail Mandel, and Richard H. Goodman \\ Division of Endocrinology, Tufts-New England Medical Center, Boston, Massachusetts 02111
}

\begin{abstract}
Although the factors controlling the secretion of the neuropeptide somatostatin have been extensively studied, little is known about the mechanisms that control somatostatin biosynthesis. Somatostatin secretion is regulated by numerous agents that increase intracellular levels of cAMP. We sought to determine whether cAMP also regulates somatostatin mRNA accumulation. We found that forskolin elicited an increase in somatostatin secretion and mRNA levels in primary cultures of rat diencephalic cells. Another secretagogue, $\mathrm{KCl}$, was as effective as forskolin in causing somatostatin secretion but had no effect on mRNA accumulation. Somatostatin expression in fibroblast cells transfected with the somatostatin gene was also regulated by forskolin. These results demonstrate that somatostatin mRNA accumulation can be regulated through a cAMP-dependent pathway, that this pathway is operative in heterologous cells transfected with the somatostatin gene, and that stimulation of somatostatin secretion and mRNA accumulation can be uncoupled from one another.
\end{abstract}

The neuropeptide somatostatin is widely distributed throughout the nervous system. In addition to its well-known role as a hypophysiotropic hormone, somatostatin also appears to serve as a neurotransmitter or neuromodulator. Somatostatin release from neurons is, in turn, regulated by a number of classical neurotransmitters and neuropeptides (for reviews, see Arimura and Fishback, 1981; Reichlin, 1983).

Although the effects of neuroregulators on the release of somatostatin have been extensively studied, little is known about the molecular mechanisms that control the synthesis of this peptide or the extent to which synthesis is regulated by factors that influence secretion. Secretion of somatostatin is increased by numerous agents that stimulate adenyl cyclase activity, including vasoactive intestinal peptide (Robbins and Landon, 1985; Tapia-Arancibia and Reichlin, 1984), glucagon (Shimatsu et al., 1982), and epinephrine (Chihara et al., 1979). Recent evidence showing that cAMP regulates the expression of several eukaryotic genes has prompted us to ask whether cAMP similarly regulates somatostatin biosynthesis and, if so, whether the regulation of somatostatin biosynthesis is obligatorily coupled to secretion of the peptide. As an index of biosynthesis, we have followed the accumulation of somatostatin mRNA. In this paper

\footnotetext{
Received July 8, 1985; revised Sept. 24, 1985; accepted Oct. 3, 1985.

We thank Karen Kelley and Robina Folland for assistance in preparing this manuscript. This work was supported by NIH Grants AM 31400, F32-NS07523, K11-AM01313, AM-16684, and P 30 AM34928. G.M. is a recipient of a research award from The Medical Foundation, Inc., Boston, MA.

Correspondence should be addressed to Dr. Montminy, Division of Endocrinology, Tufts-New England Medical Center, 171 Harrison Avenue, Boston, MA 02111 .

Copyright @ 1986 Society for Neuroscience 0270-6474/86/041171-06\$02.00/0
}

we examine the effects of forskolin, a postreceptor activator of adenyl cyclase, on somatostatin production in primary cultures of rat diencephalic cells. We demonstrate that forskolin stimulates both the secretion of immunoreactive somatostatin and the accumulation of somatostatin mRNA. To determine whether the increase in somatostatin mRNA was invariably linked to the stimulation of release, we examined the response of the cultured neurons to high concentrations of $\mathrm{K}^{+}$, a cAMP-independent secretagogue. We found that $\mathrm{K}^{+}$, in contrast to forskolin, did not increase the levels of somatostatin mRNA. As an initial step in characterizing the mechanism of cAMP induction, we transfected the rat somatostatin gene into mouse fibroblast cells, which normally do not contain somatostatin. We found that the transfected fibroblast cells produced immunoreactive somatostatin, and that the levels of both somatostatin protein and of somatostatin mRNA were increased by forskolin. We conclude that cAMP regulates somatostatin biosynthesis and secretion but that secretion of the peptide is not invariably coupled to biosynthesis.

\section{Materials and Methods}

\section{Preparation of diencephalic cultures}

Primary monolayer cultures were prepared by dissociating fetal (embryonic day 17) rat diencephalon as described previously (Delfs et al., 1980). Plating of $5 \times 10^{6}$ cells per $25 \mathrm{~cm}^{2}$ tissue culture flask was carried out in Minimal Essential Medium (Grand Island Biological Co.) containing $10 \% \mathrm{Nu}$ Serum (Collaborative Research Inc.) and Bacitracin. Seven-day-old cultures were washed with Earle's balanced salt solution (Grand Island Biochemical Co.) and then treated for 1-4 hr with medium containing either $1 \mu \mathrm{M}$ forskolin (PL Biochemicals) or $30 \mathrm{~mm} \mathrm{KCl}$

\section{Determination of somatostatin secretion}

For measurement of somatostatin secretion, the media were decanted from the treated cultures, acidified in $1 \mathrm{~N}$ acetic acid, lyophilized, and assayed for immunoreactive somatostatin (Patel and Reichlin, 1978). The antiserum used in this radioimmunoassay recognizes the midportion of the somatostatin tetradecapeptide and detects somatostatin-14 somatostatin-28, and amino-terminally extended fragments of somatostatin-28.

\section{Extraction of RNA from primary cultures}

For measurement of somatostatin mRNA, cells were washed with cold Ca-free Hank's medium and were resuspended in $10 \mathrm{~mm}$ Tris $(\mathrm{pH} \mathrm{7.0)/}$ $0.15 \mathrm{M} \mathrm{NaCl} / 2 \mathrm{~mm} \mathrm{MgCl}$ containing 10 units of RNAsin (Promega Biotech). The suspension was treated with $0.5 \% \mathrm{NP}-40$ for 5 min at $0^{\circ} \mathrm{C}$, and the nuclear pellet and cytoplasm were separated by centrifugation $(6500 \times g)$. The supernatant, containing cytoplasmic RNA, was added to an equal volume of STE buffer $(0.1 \mathrm{M} \mathrm{NaCl} / 10 \mathrm{~mm}$ Tris $(\mathrm{pH}$ 7.0)/1 mM EDTA) and extracted with phenol : chloroform. RNA in the aqueous phase was precipitated in ethanol. The RNA pellet was dissolved in $2.5 \mathrm{M} \mathrm{NH}_{4} \mathrm{Cl}$ and reprecipitated in ethanol. RNA yields were 


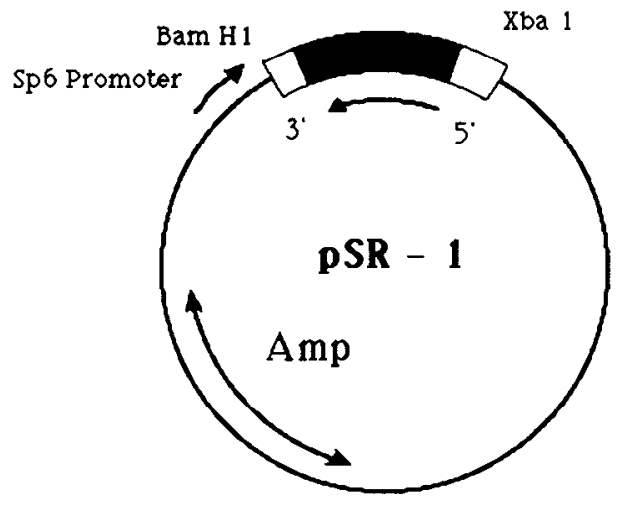

B

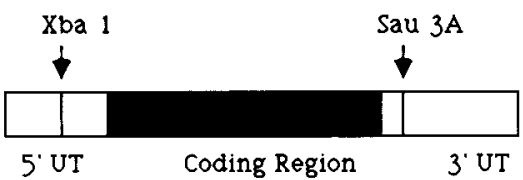

Figure 1. A, Structure of the somatostatin riboprobe vector, pSR-1. Bam $\mathrm{H} 1$ and $\mathrm{Xba} 1$ indicate the sites of insertion of the somatostatin cDNA fragment into the pSP65 vector. The 5'-to-3' orientation of the cDNA is shown with respect to the dircction of transcription from the Sp6 promoter site. $B$, Structure of the somatostatin cDNA. The Xba 1-Sau 3A fragment inserted into the pSP65 vector is delineated by arrows. $5^{\prime} \mathrm{UT}$ and $3^{\prime} \mathrm{UT}$ denote the $5^{\prime}$ and $3^{\prime}$ untranslated regions that flank the somatostatin coding segment.

quantitated by absorption at 260 and $280 \mathrm{nM} . A_{260}: A_{280}$ ratios were consistently $1.95-2.0$, indicating that the samples were essentially free of contaminating protein.

\section{Construction of the somatostatin antisense RNA hybridization probe}

Levels of somatostatin mRNA were quantitated by Northern blot hybridization using an antisense somatostatin RNA probe. The antisense RNA probe was constructed by inserting a fragment of the rat preprosomatostatin cDNA (Goodman et al., 1983) into the expression vector pSp65 (Promega Biotech) (Fig. 1). To perform this construction, pSp65 was cleaved with the restriction enzymes Xba I and Bam H1. The linearized plasmid was purified by electrophoresis on a $0.7 \%$ agarose gel. A DNA fragment containing the complete pre-prosomatostatin coding sequence in addition to a portion of the $3^{\prime}$ untranslated region was prepared by cleaving the somatostatin cDNA with the restriction enzymes Xba I and Sau $3 \mathrm{~A}$ and isolating the 450 base-pair coding sequence by agarose gel electrophoresis. The vector and somatostatin-coding sequence fragment were ligated using T4-DNA ligase. This construction places the somatostatin coding sequence in reverse orientation with respect to the bacteriophage $\mathrm{Sp} 6$ promotor and allows the generation of antisense RNA molecules. The ligated vector was introduced into competent $E$. coli $\mathrm{MC} 1061$ by calcium shock (Dagert and Ehrlich, 1979) and was amplified using standard techniques (Maniatis et al., 1982). The orientation of the somatostatin coding region within the vector was confirmed by restriction endonuclease mapping. Labeled antisense somatostatin RNA probes were prepared according to the method recommended by the manufacturer (Promega Biotech).
Northern blot hybridization assays

Five micrograms of each RNA sample were electrophoresed on a $1 \%$ agarose gel containing formaldehyde and were transferred to nitrocellulose. To confirm that each lane of the gel contained equal amounts of RNA, $5 \mu \mathrm{g}$ aliquots were also electrophoresed in parallel on nondenaturing gels stained with ethidium bromide. The ribosomal signals were quantitated by densitometry using an LKB scanner. The signal obtained using these procedures is a linear function of the amount of RNA applied (Zingg et al., 1984).

Blots were prehybridized for $3 \mathrm{hr}$ at $65^{\circ} \mathrm{C}$ in $6 \times \mathrm{SSC}(1 \times \mathrm{SSC}=$ $0.15 \mathrm{M} \mathrm{NaCl}, 0.015 \mathrm{M} \mathrm{Na}$ citrate $), 5 \times$ Denhardt's $(1 \times$ Denhardt's $=$ $0.02 \%$ polyvinylpyrrolidone, Ficoll, and BSA), $50 \%$ formamide, 100 $\mu \mathrm{g} / \mathrm{ml}$ salmon sperm DNA, and were hybridized for $48 \mathrm{hr}$ under the same conditions with $4 \times 10^{6} \mathrm{cpm} / \mathrm{ml}$ of the antisense RNA probe. Blots were washed $3 \times$ at $65^{\circ} \mathrm{C}$ in $2 \times \mathrm{SSC} / 0.1 \% \mathrm{SDS}$, followed by three washes at the same temperature in $0.2 \times \mathrm{SSC} / 0.1 \% \mathrm{SDS}$. Autoradiograms were developed after exposure to $\mathrm{x}$-ray film for $4 \mathrm{hr}$ at $-80^{\circ} \mathrm{C}$ using an intensifying screen. The intensity of hybridizing signals was quantitated by densitometry.

\section{Gene constructions and transfections}

NIH 3T3 fibroblast cells were transfected with the plasmid D3pSal (Fig. 2), which contains the rat somatostatin gene (Montminy et al., 1984) extending from 750 base pairs upstream from the promoter to 3 kilobases downstream from the coding sequence.

Cells were transfected using the calcium phosphate coprecipitation technique (Graham and Van der Eb, 1973). For 10 3T3 cells, 10-20 $\mu \mathrm{g}$ of D3pSal and $1 \mu \mathrm{g}$ of the selectable marker pSV2neo were used. Cotransfection with the plasmid pSV2neo allows the selection of stably transformed cells that have integrated the neomycin-resistance gene into their genome (Southern and Berg, 1982). These cells can be selected by their ability to grow on the neomycin analog G418. Transfected cells were grown in Dulbecco's Minimal Essential Medium, containing 10\% calf serum, penicillin-streptomycin, and $400 \mu \mathrm{g} / \mathrm{ml} \mathrm{G418.} \mathrm{After} 2$ weeks of selection, G418-resistant clones were subcultured and analyzed for their ability to produce immunoreactive somatostatin. Clones that produced somatostatin were maintained in culture for further analysis.

\section{Southern blot analysis of transfected cell lines}

Stable integration of the somatostatin gene into fibroblast cells was demonstrated by Southern blot analysis. Genomic DNA was prepared from 3T 3 cells transfected with the somatostatin gene using the method of Blin and Stafford (1976). Cells from confluent $100 \mathrm{~mm}$ dishes were harvested and treated with NP40 as described for mRNA extractions. Nuclear pellets were resuspended in $200 \mu$ STE supplemented with $0.1 \%$ SDS, then treated with proteinase $\mathrm{K}(200 \mu \mathrm{g} / \mathrm{ml})$ for $3 \mathrm{hr}$. The viscous solutions were extracted $3 \times$ with phenol : chloroform and were subsequently dialyzed extensively against TE (10 mM Tris, $\mathrm{pH} 8 / 1 \mathrm{~mm}$ EDTA). Five micrograms of genomic DNA from each sample were digested with the restriction enzyme Eco $\mathrm{R} 1$, and the samples were electrophoresed on a $0.7 \%$ agarose gel alongside a Hind III-digested lambda-DNA size marker. The gel was denatured, blotted onto nitrocellulose, and prehybridized as described previously (Montminy et al., 1984). The blot was hybridized with $10^{7} \mathrm{cpm} / \mathrm{ml}{ }^{32} \mathrm{P}$-labeled somatostatin antisense RNA for $15 \mathrm{hr}$. After hybridization, the blot was washed $3 \times$ at $50^{\circ} \mathrm{C}$ in $2 \times \mathrm{SSC} / 0.1 \%$ SDS followed by three washes in $0.2 \times$ SSC/0.1\% SDS. Hybridizing bands were detected by autoradiography.

\section{Results}

Somatostatin secretion was measured in primary cultures of embryonic day 17 rat diencephalic cells in the basal state and after administration of forskolin. These cultures contain approximately $3 \%$ somatostatin-producing cells (Delfs et al., 1980). Forskolin $(1 \mu \mathrm{M})$ caused a twofold increase in somatostatin secretion over a period of $4 \mathrm{hr}$ (Fig. 3), consistent with previous studies (Robbins et al., 1982). To determine whether the increase in somatostatin secretion caused by forskolin was associated with an increase in somatostatin mRNA accumulation, we performed Northern blot hybridization assays. Preliminary studies showed that the level of sensitivity obtained using conventional nick-translated cDNA hybridization probes was not sufficient to allow us to detect somatostatin mRNA in the pri- 


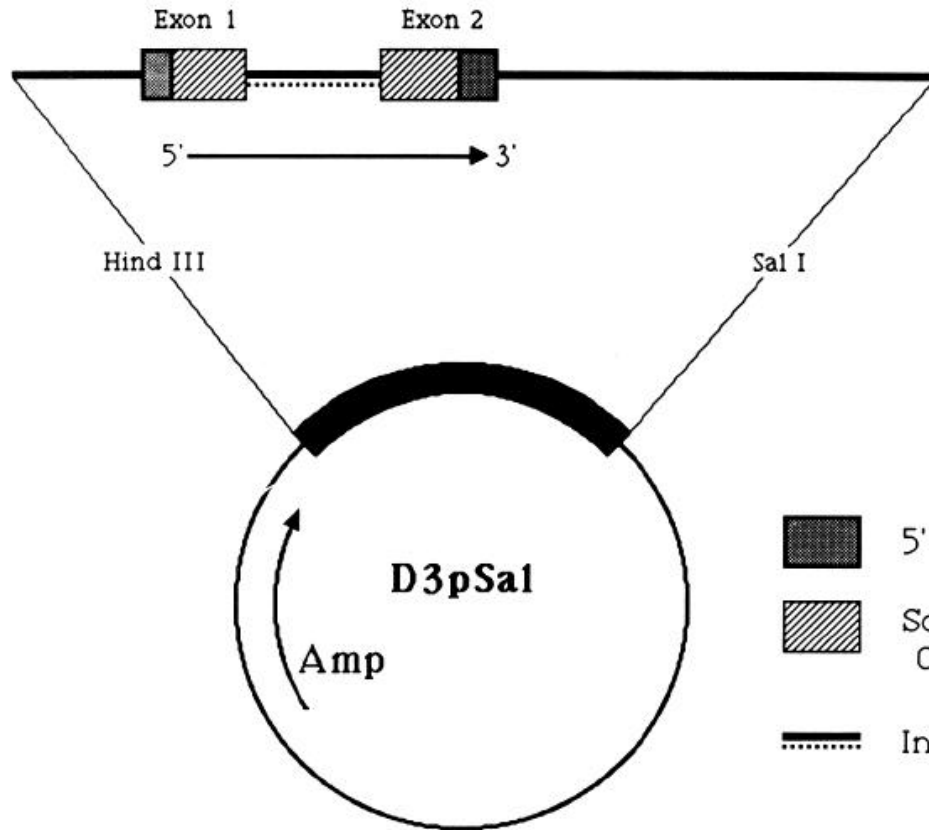

$5^{\prime}$ and $3^{\prime}$ UT

Somatostatin Coding Sequence

Intron Sequence
Figure 2. Structure of D3pSal. This plasmid contains the somatostatin gene extending 750 base pairs upstream from the promoter to 3 kilobases downstream from the coding sequence. This fragment was cloned into the Hind IIISal 1 sites of the plasmid pBR 322. The two exons and single intervening sequence are indicated. mary diencephalic cultures. Consequently, we generated antisense somatostatin mRNA probes capable of detecting less than $1 \mathrm{pg}$ of somatostatin mRNA. Relatively stringent conditions $\left(65^{\circ} \mathrm{C}, 50 \%\right.$ formamide, $\left.6 \times \mathrm{SSC}\right)$ were found to be necessary to eliminate nonspecific hybridization to ribosomal RNA. De- spite these stringent conditions, hybridization to a 650 base RNA from the primary cultures was easily detected. This 650 base RNA comigrated with an RNA species shown previously to encode the rat somatostatin precursor (Goodman et al., 1983).

The increase in somatostatin secretion seen after $4 \mathrm{hr}$ of for-

A

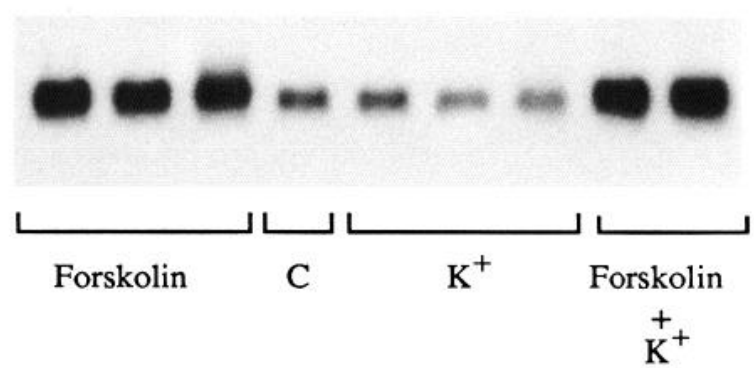

B

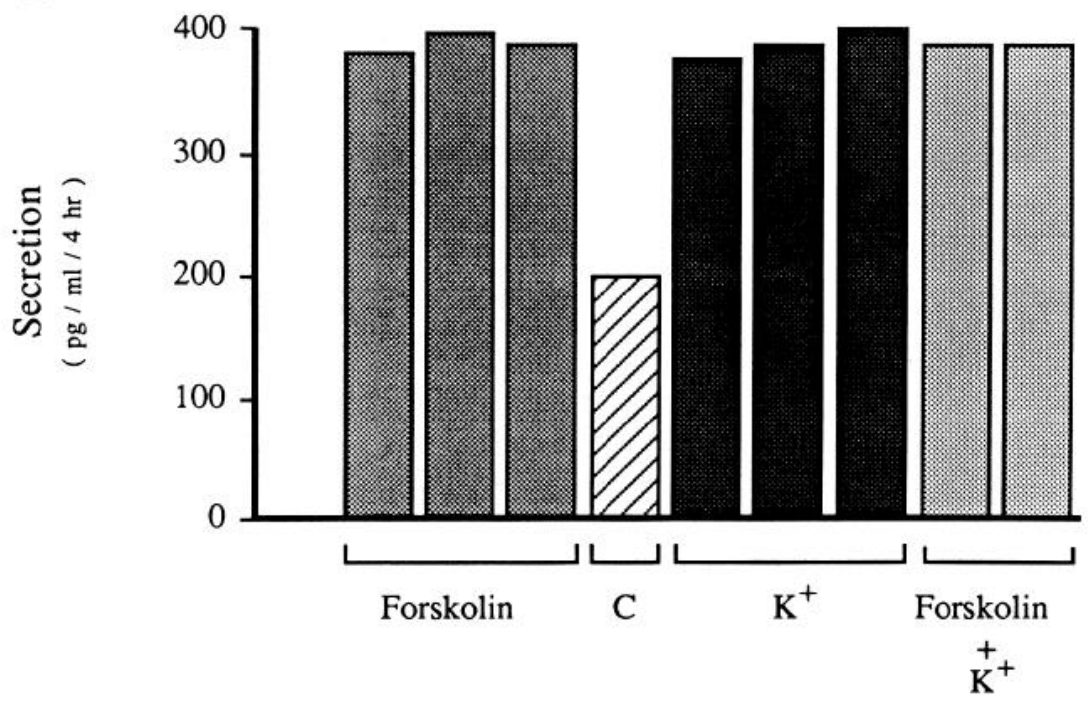

Figure 3. Stimulation of somatostatin mRNA accumulation and somatostatin secretion in primary cultures of diencephalic cells. $A$, Autoradiogram of a Northern blot containing diencephalic cell cytoplasmic RNA hybridized with a ${ }^{32}$ P-labeled somatostatin antisense RNA probe. Individual treatments with $10^{-6}$ м forskolin, control (C), $30 \mathrm{~mm}$ $\mathrm{KCl}\left(\mathrm{K}^{+}\right)$, or forskolin $+\mathrm{KCl}$ are indicated. $B$, Corresponding immunoreactive somatostatin levels in the media following treatment with these agents. Immunoreactive somatostatin media levels and corresponding mRNA levels were measured from the same culture dish for each treatment. 
1

$2 \quad 3 \quad 4$

Kilobases

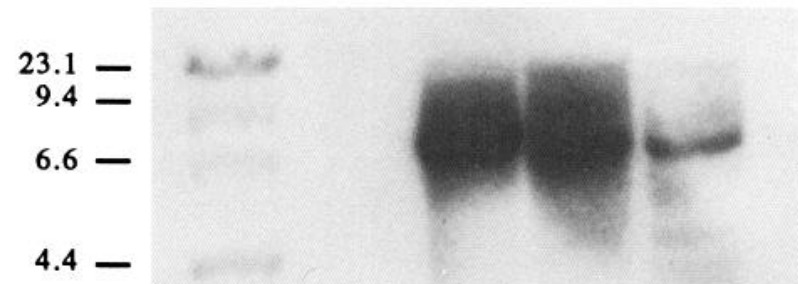

$2.3-$

$2.0-$
Table 1. Secretion of somatostatin from transfected $3 T 3$ cells in response to forskolin

\begin{tabular}{|c|c|c|c|}
\hline & \multicolumn{2}{|c|}{$\begin{array}{l}\text { Somatostatin secretion } \\
(\mathrm{pg} / \mathrm{ml} / 18 \mathrm{hr})\end{array}$} & \multirow[b]{2}{*}{$\begin{array}{l}\text { Increase } \\
(\%)\end{array}$} \\
\hline & Basal & $\begin{array}{l}\text { Forskolin- } \\
\text { stimulated }\end{array}$ & \\
\hline D3pSal5 & 916 & 1924 & 210 \\
\hline D3pSal7 & 20 & 38 & 190 \\
\hline D3pSal8 & 143 & 460 & 322 \\
\hline
\end{tabular}

Individual culture plates containing $10^{7}$ cells were treated either with nothing (Basal) or $10^{-6} \mathrm{M}$ forskolin for $18 \mathrm{hr}$. Media samples from each plate were then collected and assayed for immunoreactive somatostation. D3pSal5, D3pSal7, and D3pSal8 represent three individually transfected $3 \mathrm{~T} 3$ cell clones.

skolin treatment was accompanied by a three- to fourfold increase in somatostatin mRNA (Fig. 3). To determine whether the increase in somatostatin mRNA was a consequence of somatostatin secretion per se, we treated the diencephalic cells with $30 \mathrm{~mm} \mathrm{KCl}$. This level of $\mathrm{KCl}$ was as effective as forskolin in stimulating somatostatin secretion but had no effect on somatostatin mRNA accumulation (Fig. 3). To assure that $\mathrm{KCl}$ did not have a toxic effect on the diencephalic cells, somatostatin mRNA levels were assayed in cells treated with $\mathrm{KCl}$ and forskolin. The somatostatin mRNA levels in these cells were no different from those in cells treated with forskolin alone, indicating that $30 \mathrm{~mm} \mathrm{KCl}$ does not have a toxic effect on mRNA accumulation.

As a first step toward characterizing the mechanism by which cAMP induces somatostatin biosynthesis, we introduced the cloned rat somatostatin gene into heterologous cells. The host cells for these studies, NIH-3T3 fibroblasts, do not normally produce somatostatin. We used the $\mathrm{CaPO}_{4}$ technique (Graham and Van der Eb, 1973) to cotransfect 3 T3 cells with the somatostatin gene and the selectable marker pSV2neo.

Three stably transfected cell lines were assayed by Southern blot analysis for integration of the somatostatin gene (Fig. 4). The fragments detected in EcoR1-digested cellular DNA indicated that between 20-30 copies of the somatostatin gene had integrated in a head-to-tail fashion and were not rearranged. Somatostatin mRNA expressed by these cells was the same size

Figure 4. Southern blot of genomic DNA from three individual NIH$3 \mathrm{~T} 3$ cell clones transfected with the rat somatostatin gene. Lane 1, Size marker with respective sizes in kilobases listed alongside; lanes 2-4 3T3 cell genomic DNA from three independently isolated cell clone transfected with the plasmid D3pSal (see Fig. 2). DNA samples were digested to completion with the restriction enzyme, EcoR1. All three lanes show two major hybridizing EcoR1 bands of 1 and 7.2 kilobases.

These sizes coincide with the fragments predicted from the structure of D3pSal. Lanes 2-4 contain genomic DNA from the transfected clones D3pSal5, D3pSal7, and D3pSal8, respectively.

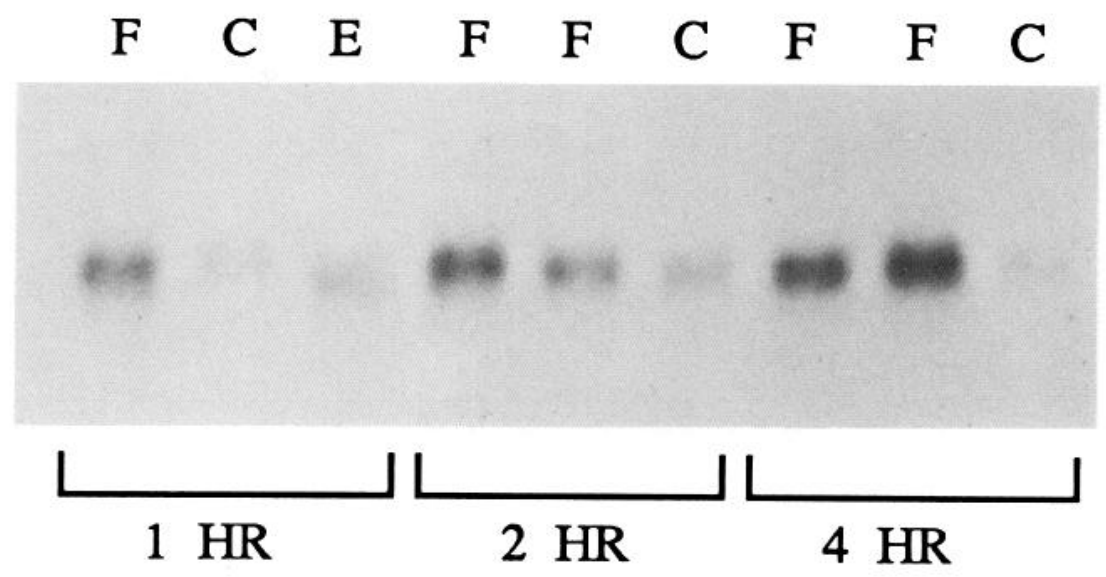

Figure 5. Time course of forskolin-induced somatostatin mRNA accumulation in transfected 3T3 cells. This autoradiogram of a Northern blot depicts the amount of hybridizable somatostatin mRNA in either control $(C), 0.1 \%$ ethanol- $(E)$, or $10^{-6} \mathrm{M}$ forskolin- $(F)$ treated cells. Individual culture dishes containing $10^{7}$ cells were harvested after 1,2 , and $4 \mathrm{hr}$ of treatment. The corresponding cytoplasmic RNAs were prepared and analyzed for somatostatin mRNA accumulation. Ethanol treatment was performed because forskolin powder was initially dissolved in $100 \%$ ethanol prior to dilution into medium. Final ethanol concentration in forskolin-treated samples was also $0.1 \%$. In this and other experiments, the effect of ethanol on somatostatin mRNA accumulation was negligible. This experiment was performed on a single transfected clone, D3pSal5. However, the two other transfected 3T3 lines, D3pSal7 and D3pSal8, showed similar somatostatin mRNA induction in response to forskolin. 
as that found in normal somatostatin-producing tissues (Goodman et al., 1983). Gel-filtration chromatography of immunoreactive somatostatin elaborated by the transfected cells revealed primarily higher molecular weight forms with negligible amounts of biologically active somatostatin- 14 or -28 peptides (data not shown). These cells apparently do not possess the processing enzymes necessary for the production of either of these bioactive forms.

Unlike neuronal cells, the transfected 3T3 cells did not appear to store somatostatin efficiently. More than $90 \%$ of the immunoreactive somatostatin produced by the transfected cells was found in the media. Therefore, we have used both the cellular mRNA levels and the media levels of immunoreactive somatostatin as indices of somatostatin biosynthesis.

To determine whether cAMP could modulate expression of the somatostatin gene in a heterologous cell, we analyzed somatostatin mRNA levels in the $3 \mathrm{~T} 3$ cells before and after treatment with forskolin. In each of the three transfected cell lines, somatostatin mRNA levels increased within $1 \mathrm{hr}$ and became maximal (8 to 10-fold increase) within $4 \mathrm{hr}$ of forskolin treatment (Fig. 5). Somatostatin mRNA was not detectable in nontransfected 3T3 cells exposed to $1 \mu \mathrm{M}$ forskolin.

After exposure to $1 \mu \mathrm{M}$ forskolin, the $3 \mathrm{~T} 3$ cell lines transfected with the somatostatin gene also increased their production of immunoreactive somatostatin 2-3× (Table 1). This increase in immunoreactive somatostatin was additionally seen after treatment of the cells with cholera toxin $(1 \mu \mathrm{g} / \mathrm{ml})$ and $1 \mathrm{mM}$ dibutyryl cAMP, agents also known to increase intracellular levels of cAMP (data not shown). These studies indicate that cAMP increases expression of the transfected somatostatin gene at the level of mRNA accumulation and that the increased mRNA levels are associated with an increased synthesis of the peptide.

\section{Discussion}

The purpose of our studies was to determine whether somatostatin biosynthesis was modulated by factors that regulate somatostatin secretion. We chose to examine the effects of forskolin, an agent that elevates intracellular levels of cAMP through a postreceptor mechanism. Cyclic AMP-dependent mechanisms appear to represent a common pathway for agents that have been shown to influence somatostatin secretion (Reichlin, 1983).

Forskolin caused an increase in both somatostatin secretion and mRNA levels in cultured diencephalic cells. These results suggested that somatostatin mRNA accumulation might be coupled to secretion of the peptide. We considered two alternative hypotheses to explain these observations. The first, a cellular depletion model, proposed that somatostatin biosynthesis is regulated by intracellular levels of the neuropeptide. In this modcl, somatostatin secretion would be expected to stimulate somatostatin mRNA accumulation by depleting peptide stores. The second model proposed that cAMP could stimulate somatostatin mRNA accumulation and peptide secretion independently.

We tested these hypotheses by treating the cultured cells with $\mathrm{KCl}$ at levels that were as effective as cAMP in stimulating somatostatin secretion. $\mathrm{KCl}$ did not increase somatostatin mRNA levels. These results demonstrated that secretion of somatostatin could be uncoupled from mRNA accumulation.

To determine whether the CAMP-dependent regulation of somatostatin production occurred only in normal somatostatinproducing cells, we transfected mouse fibroblast cells with a somatostatin gene construction that contained 750 base pairs of the $5^{\prime}$ flanking region. Three G418-resistant cell lines that expressed the foreign somatostatin gene were identified. Each of these cell lines responded to forskolin by increasing their production of somatostatin mRNA and immunoreactive protein. These studies indicate that all of the sequences necessary for regulation by CAMP are contained within the 4.2 kilobase gene fragment and that the increase in somatostatin mRNA, at least in fibroblast cells, is associated with an actual increase in biosynthesis of the peptide.

Our data for cAMP induction of somatostatin mRNA accumulation do not discriminate between increased transcriptional rate, increased precursor splicing, or decreased degradation of the mature somatostatin mRNA. However, we have recently observed that a fusion gene containing the somatostatin promoter ligated to the bacterial marker chloramphenicol acetyl transferase (CAT), is also regulated by cAMP when transfected into the neuroendocrine cell line PC12 (M. R. Montminy et al., unpublished observations). In contrast, a fusion gene containing the SV40 promoter linked to the CAT gene is not activated by cAMP. These studies suggest that the cAMP responsiveness that we observed affects the somatostatin gene specifically, and that the sequences essential for induction are found in the $5^{\prime}$ flanking region of the gene.

Other cAMP-inducible eukaryotic genes have recently been identified, including that coding for prolactin (Murdoch et al., 1982) and proenkephalin (Eiden et al., 1984). A 620 base-pair DNA fragment upstream from the rat phosphoenolpyruvate carboxykinase gene has been identified that confers cAMP inducibility when fused to the promoter of the Herpes thymidine kinase gene (Wynshaw-Boris et al., 1984). This latter effect appears to be tissue-specific, as the induction is seen only in transfected hepatoma cells. The cAMP regulatory region that we have identified in the rat somatostatin gene, on the other hand, is functional in $3 \mathrm{~T} 3$ cells, which do not normally produce somatostatin.

In summary, our studies suggest that somatostatin secretion and somatostatin mRNA accumulation are independently regulated by cAMP. Our findings further suggest that some of the factors that increase activity of somatostatinergic neurons may also be able to influence somatostatin biosynthesis. Neurotransmitters such as dopamine that increase adenyl cyclase activity may differ in this regard from other factors that stimulate somatostatin release without elevating intracellular levels of cAMP.

\section{References}

Arimura, A., and J. B. Fishback (1981) Somatostatin: Regulation of secretion. Neuroendocrinology 33: 246-256.

Blin, N., and D. W. Stafford (1976) Isolation of high molecular weight DNA. Nucleic Acids Res. 3: 2303-2310.

Chihara, K., A. Arimura, and A. V. Schally (1979) Effect of intraventricular injection of dopamine, norepinephrine, acetylcholine, and 5-hydroxytryptamine on immunoreactive somatostatin release into rat hypophyseal portal blood. Endocrinology 104: 1656-1662.

Dagert, M., and S. D. Ehrlich (1979) Prolonged incubation in calcium chloride improves the competence of Escherichia coli cells. Gene 6: 23-30.

Delfs, J., R. Robbins, J. Connolly, M. Dichter, and S. Reichlin (1980) Somatostatin production by rat cerebral neurons in dissociated cell culture. Nature 283: 676-677.

Eiden, L. E., P. Girand, H. U. Affolter, E. Herbert, and A. J. Hotchkiss (1984) Alternative modes of enkephalin biosynthesis regulation by reserpine and cyclic AMP in cultured chromaffin cells. Proc. Natl. Acad. Sci. USA 81: 3949-3953.

Goodman, R. H., D. C. Aron, and B. A. Roos (1983) Rat pre-prosomatostatin: Structure and processing by microsomal membranes. J. Biol. Chem. 258: 5571-5573.

Graham, F., and A. J. Van der Eb (1973) A new technique for the assay of infectivity of human adenovirus 5 DNA. Virology 52: 456467.

Hermansen, K. (1980) Effects of substance $P$ and other peptides on the release of somatostatin, insulin, and glucagon in vitro. Endocrinology 107: 256-261.

Maniatis, T., E. F. Fritsch, and J. Sambrook (1982) Molecular Cloning-A Laboratory Manual, Cold Spring Harbor Laboratory, Cold Spring Harbor, NY. 
Montminy, M. R., R. H. Goodman, S. J. Horovitch, and J. F. Habener (1984) Primary structure of the gene encoding rat pre-prosomatostatin. Proc. Natl. Acad. Sci. USA 81: 3337-3340.

Murdoch, G. H., M. G. Rosenfeld, and R. M. Evans (1982) Eukaryotic transcriptional regulation and chromatin associated protein phosphorylation by cyclic AMP. Science 218: 1315-1317.

Patel, Y., and S. Reichlin (1978) Somatostatin in hypothalamus, extrahypothalamic brain, and peripheral tissues of the rat. Endocrinology 102: 523-530.

Reichlin, S. (1983) Somatostatin. N. Engl. J. Med. 309: 1495-1501, 1556-1563.

Robbins, R. J., and R. M. Landon (1985) The effects of neurotensin, vasoactive intestinal polypeptide, and other neuropeptides on the secretion of somatostatin from cerebral cortical cells. Brain Res. 332: 161-164.

Robbins, R. J., R. E. Sutton, and S. Reichlin (1982) Effects of neurotransmitters and cyclic AMP on somatostatin release from cultured cerebral cortical cells. Brain Res. 234: 377-386.
Shimatsu, A., Y. Kato, N. Matsushita, H. Katakami, N. Yanaihara, and H. Imura (1982) Effects of glucagon, neurotensin, and vasoactive intestinal polypeptide on somatostatin release from perifused rat hypothalamus. Endocrinology 110: 2113-2117.

Southern, P., and P. Berg (1982) Mammalian cell transformation with SV40 hybrid plasmic vectors. Mol. Appl. Genet. 1: 327-333.

Tapia-Arancibia, L., and S. Reichlin (1984) Vasoactive intestinal polypeptide and PHI stimulate somatostatin release from rat cerebral cortical and diencephalic cells in dispersed cell culture. Brain Res.

Wynshaw-Boris, A., T. Gross Lugo, J. M. Short, R. E. K. Fournier, and R. W. Hanson (1984) Identification of a cAMP regulatory region in the gene for rat cytosolic phosphoenolpyruvate carboxykinase (GTP). J. Biol. Chem. 259: 12161-12169.

Zingg, H. H., R. H. Goodman, and J. F. Habener (1984) Developmental expression of the rat somatostatin gene. Endocrinology 115 : 90-94. 